\title{
Güneş Panellerinde Cuk Dönüştürücü Tabanlı Değişken Şartlar Altında D\&G, BM ve YSA Algoritmalarının Karşılaştırmalı Performans Analizi
}

\section{Through Cuk Converter in Solar Panels Comparative Performance Analysis of P\&O, FL and ANN Algorithms under Variable Condition}

Geliş / Received: 24/04/2019

Okan GÜNGÖR ${ }^{1 *}$

Revize / Revised: 25/05/2019

Kabul / Accepted: 26/05/2019

z- Güneş enerjisinden elektrik üretmekte kullanılan PV panellerin verim artırma çalışmaları devam etmektedir. Verimi etkileyen unsurların başında MGNT algoritmaları gelmektedir. Bu çalışmada sezgisel (BM, YSA) ve D\&G tabanlı MGNT algoritmaları incelenmiştir. Sezgisel algoritmaların uygulanabilmesi için Cuk dönüştürücüye ait denetleç tasarımı Matlab aracılığıyla yapılmıştır. Yapılan benzetim çalışmaları sonucunda, üç farklı MGNT algoritmasının performans analizleri gösterilmiştir.

Anahtar Kelimeler - Maksimum Güç Noktası Takibi, Bulanık Mantık, Yapay Sinir Ağları, Cuk Dönüştürücü

\begin{abstract}
bstract- Efforts to increase the efficiency of PV panels used in electricity generation from solar energy continue. MPPT algorithms are at the forefront of the factors affecting efficiency. In this work, heuristic (FL, ANN) and P\&O based MPPT algorithms have been investigated. In order to apply heuristic algorithms, controller design of Cuk converter have been done by using Matlab. As a result of the simulation studies, performance analyzes of three different MGNT algorithms have been shown.
\end{abstract}

Keywords - Maximum Power Point Tracking, Fuzzy Logic, Artificial Neural Networks, Cuk Converter

\section{GİRIŞ}

Güneş 1şığını elektrik enerjisine dönüştüren fotovoltaik hücrelerin verim artırma çalışmaları güncel olarak devam etmektedir [1]. Verim, hücrelerden oluşan modül için dönüştürücü tercihinden, seçilen MGNT (Maksimum Güç Noktası Takibi) algoritmalarının değişken şartlardaki (radyasyon değişimi, yük değişimi, vs.) performansından etkilenmektedir. Bu sebeple literatürde, güneş panellerinden maksimum gücü elde etmek için pek çok dönüştürücü ve algoritma odaklı çalışma yapılmaktadır [2-4].

Güneş panellerinde MGNT uygulamaları için dönüştürücü odaklı çalışmalarda çeşitli türlerde dönüştürücüler kullanılmıştır [5-7]. Yapılan çalışmalarda Buck dönüştürücünün panel iç direncinden büyük bir resistif yük bağlanması durumunda MGN'yi (Maksimum Güç Noktası) bulamadığı ortaya koyulmuştur. Boost dönüştürücünün ise panel iç direncinden küçük bir resistif yük bağlanması durumunda MGN'yi takip edemediği gösterilmiştir [8]. Bu sebeplerden dolayı bu çalışmada panel ve bağlanan yükleri dikkate almaksızın MGN yapabilmesi nedeniyle Cuk dönüştürücü tercih edilmiştir [9].

Güneş panellerinde MGNT uygulamaları için algoritmik olarak yapılan çalışmalar çevrim içi ve çevrim dışı olarak ikiye ayrılmaktadır [10]. Çevrim içi algoritmalar, panelin çıkışa aktardığı gücü eski panel çıkış gücüyle kıyaslayarak referans sinyalini maksimum güç noktasına doğru yönlendirmektedir.

1*Sorumlu yazar iletişim: okangungor@bayburt.edu.tr (https://orcid.org/0000-0001-5258-1765)

Elektronik ve Otomasyon Bölümü, Bayburt Üniversitesi, Baberti Külliyesi, Bayburt, Türkiye 
Bu teknikte yer alan D\&G (Değiştir ve Gözle), Aİ (Artımsal İletkenlik) ve PSO (Parçacık Sürü Optimizasyonu) algoritmaları literatürde yaygın olarak kullanılmaktadır. Çevrim dışı algoritmalar ise panellerin parametrelerinin (panel radyasyon seviyesi, panel sıcaklığı, panel kısa devre akımı ve panel açık devre gerilimi) detaylı bir şekilde önceden tespiti odaklı çalışır. Bazı yapay zekâ teknikleri de (YSA, BM, ANFIS) yaygın olarak bu başlık altında yer almaktadır.

Yapılan çalışmada algoritmik olarak ise maksimum gücü takip etmek için çevrim içi algoritmalardan $\mathrm{D} \& \mathrm{G}$, çevrim dışı algoritmalardan BM (Bulanık Mantık) ve YSA (Yapay Sinir Ağları) tabanlı MGNT algoritmaları incelenmiştir. Yapılan bu çalışmanın odak noktası iki farklı sınıfta bulunan MGNT algoritmaların performansını farklı koşullar (radyasyon, yük) altında analiz etmektir. Bu sebeple dönüştürücülerin panel gücünü yüke aktarırken oluşan güç kaybını göz ardı ederek, sadece MGNT algoritmalarının performanslarını inceleyebilmek için güç ölçümü panel çıkışından yapılmıştır.

\section{D\&G YARDIMIYLA MGNT}

Literatürde D\&G algoritmasında referans olarak seçilecek denetim değişkeni gerilim, akım veya görev süresidir [10]. Eğer denetim değişkeni olarak görev süresi seçilirse matematiksel bir modelleme işlemi yapılmadan dönüştürücü doğrudan denetlenebilir $[11,12]$. Denetim değişkeni olarak akım veya gerilim seçilirse denetleç tasarımına ihtiyaç duyulmaktadır. Bu şekildeki denetime de dolaylı denetim denilmektedir [13].

Çalışmamızda gözlem değişkeni olarak görev süresi seçilmiştir. D\&G algoritmasının çalışma prensibi: Panel çıkış gücünü ve panel çıkış gerilimini takip ederek görev süresini belirlemektir. Aşağıda akış tablosu (Şekil 2) ve panel karakteristik eğrilerinde (Şekil 1) bu durum görsel olarak anlatılmış olup, benzetim çalışmaları kısmında uygulanmıştır.

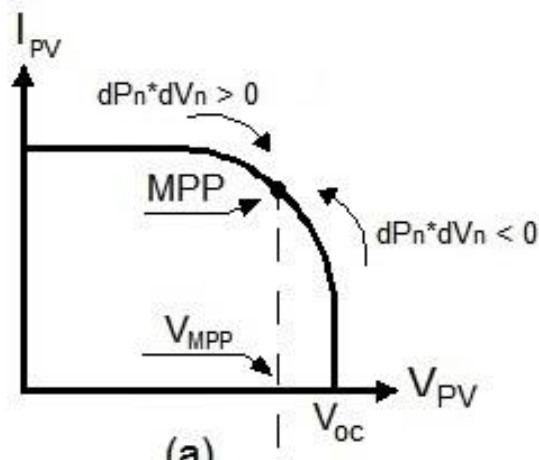

(a)

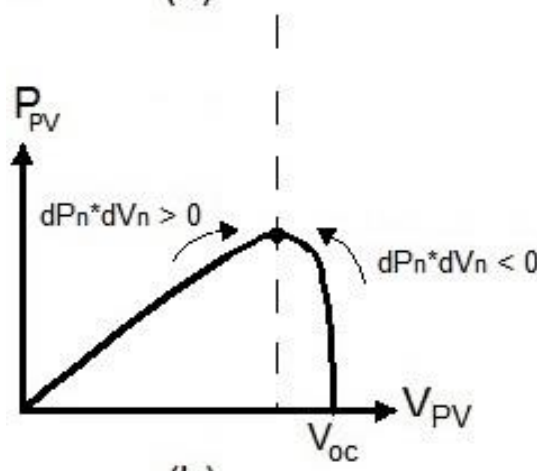

(b)

Şekil 1. PV panel P-V a) ve I-V (b) karakteristik eğrileri

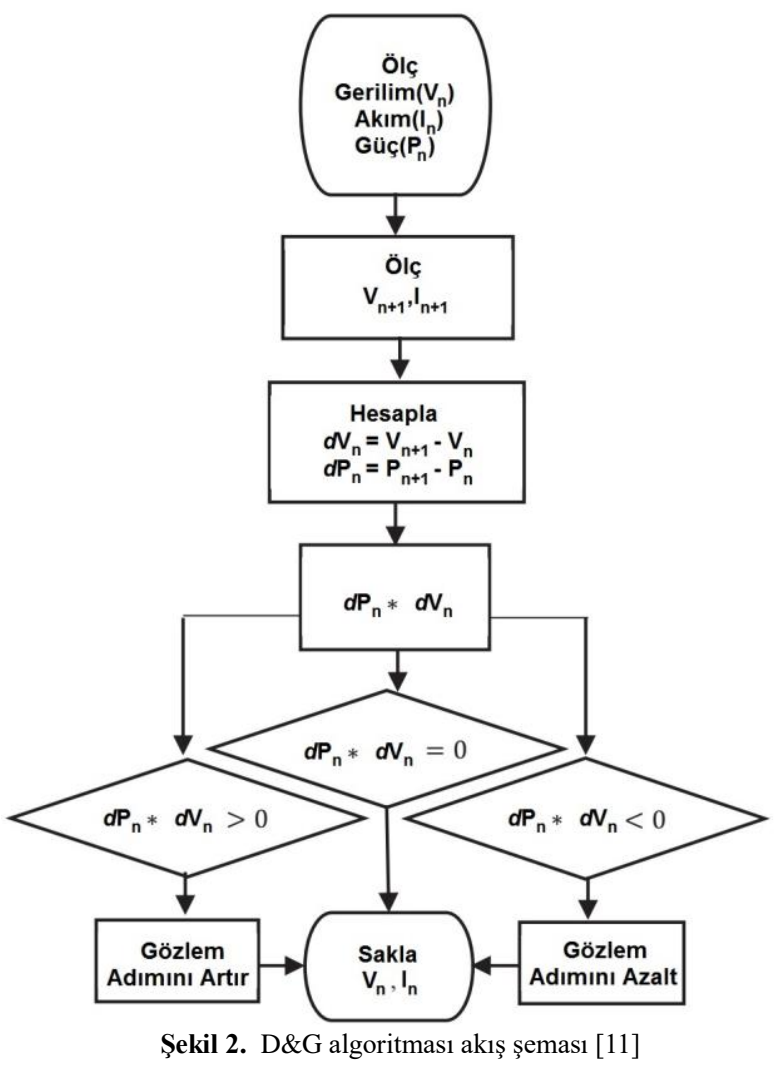

Şekil 2. D\&G algoritması akış şeması [11]

\section{BM YARDIMIYLA MGNT}

Bulanık mantık sözel ifadeler yardımıyla belirsizlikler üzerinden hedefe ulaşmaya çalışır. Kesinliklerin yerine belirsizlikleri kullanarak hedefe ulaşan bulanık mantık bu yönüyle diğer yapay zeka yöntemlerinden ayrışır. Bu çalışmada bulanık mantık yardımıyla maksimum güç noktasındaki akımı belirlenmektedir. Şekil 3'de bulanık mantık genel yapısı sunulmuştur. 


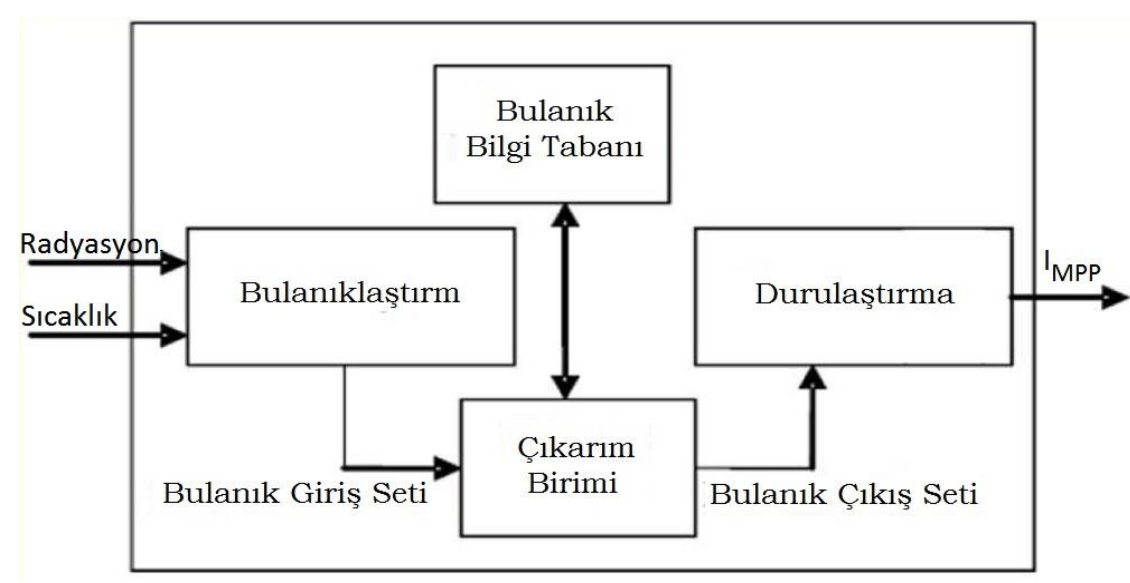

Şekil 3. Bulanık mantık genel şeması

MGN'deki akım değerini, sıcaklık ve radyasyon değerlerini sözel ifadelere dönüştürmek ve bu ifadeleri bulanıklaştırmak için üçgen üyelik fonksiyonları yardımıyla bulanıklaştırma işlemi yapılmıştır. Aşağıda bu çalışmada kullanılan bulanık mantık üyelik fonksiyonları sunulmuştur.

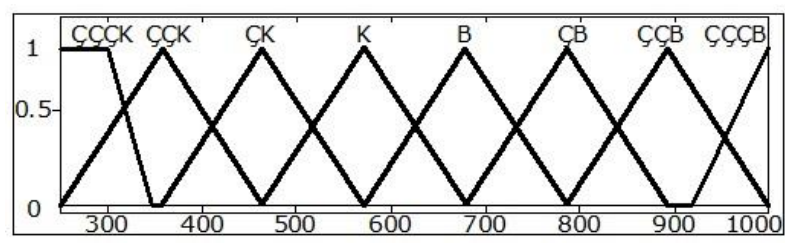

Şekil 4. Radyasyon giriş değişkeni üyelik fonksiyonları

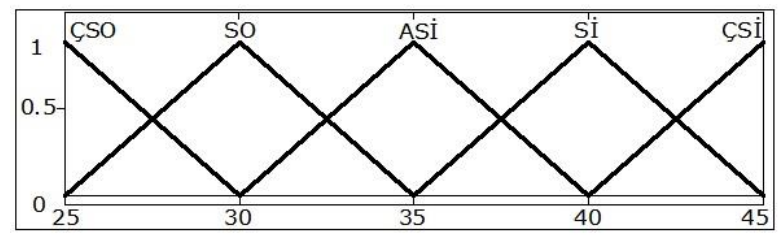

Şekil 5. Sıcaklık giriş değişkeni üyelik fonksiyonları

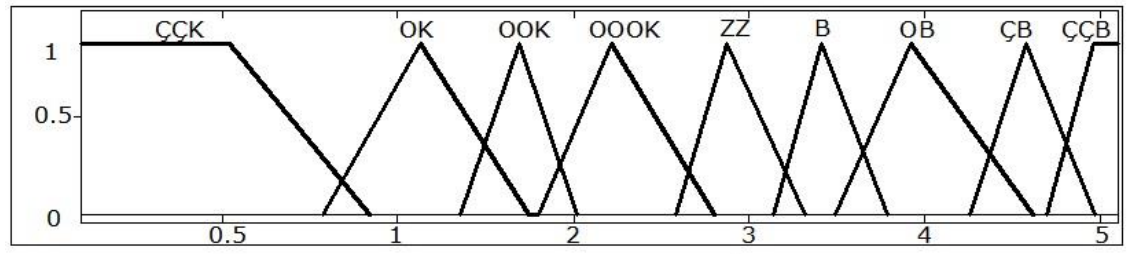

Şekil 6. Akım referansı çıkış değişkeni üyelik fonksiyonları

Bulanık mantık denetleçine radyasyon ve sıcaklık giriş olarak alınmıştır. Çıkış olarak ise referans akım elde edilmiştir. Sekiz adete üyelik fonksiyonu ile radyason için bulanıklaştırma yapılmıştır (ÇÇÇK: Çok çok çok küçük radyasyon, ÇÇK:Çok çok küçük radyasyon, ÇK:Çok küçük radyasyon, K:Küçük radyasyon, B:Büyük radyasyon, ÇB: Çok büyük radyasyon, ÇÇB: Çok çok büyük radyasyon, ÇÇÇB: Çok çok çok büyük radyasyon). Beş adete üyelik fonksiyonu ile de sıcaklık için bulanıklaştırma yapılmıştır (ÇSO: Çok soğuk, SO: Soğuk, ASİ: Az sıcak, Sİ: Sıcak, ÇSİ: Çok sıcak). Çıkış olarak MGN'deki referans akım değeri için ise dokuz adet üyelik fonksiyonu seçilmiştir (ÇÇK:Çok çok küçük akım, OK:Ortalama küçük akım, OOK: Ortalama orta küçük akım ,OOOK: Orta orta ortalama küçük akım , ZZ:Ortalama akım ,B:Büyük akım,OB:Ortalama büyük akım, ÇB:Çok büyük akım,ÇÇB:Çok çok büyük akım ). 
Aşağıda verilen kural tablosu yardımıyla, Mamdani bulanık çıkarım yöntemi kullanılmıştır.

Tablo 1. Kural tablosu

\begin{tabular}{|c|c|c|c|c|c|}
\hline Rad/Sıc & ÇSO & SO & ASI & Sí & ÇSI \\
\hline ÇÇÇK & OK & ÇÇK & ÇÇK & ÇÇK & ÇÇK \\
\hline ÇÇK & OOK & OOK & OK & OK & ÇÇK \\
\hline ÇK & OOOK & OOOK & OOOK & OOK & OK \\
\hline $\mathbf{K}$ & $\mathrm{ZZ}$ & $\mathrm{ZZ}$ & $\mathrm{ZZ}$ & $\mathrm{OOOK}$ & $\mathrm{OOK}$ \\
\hline $\mathbf{B}$ & $\mathrm{B}$ & $\mathrm{B}$ & $\mathrm{B}$ & $\mathrm{ZZ}$ & $\mathrm{ZZ}$ \\
\hline $\mathbf{C ̧ B}$ & $\mathrm{OB}$ & $\mathrm{OB}$ & $\mathrm{OB}$ & $\mathrm{OB}$ & $\mathrm{B}$ \\
\hline ÇÇB & ÇB & ÇB & ÇB & ÇB & ÇB \\
\hline ÇÇÇB & ÇÇB & ÇÇB & ÇÇB & ÇÇB & ÇB \\
\hline
\end{tabular}

Ağırlıklı ortalama yöntemi yardımıyla, bulanık ifadelerden oluşan sözel ifadeleri sayısal değerlere dönüştürerek durulaştırma işlemi gerçekleştirilmiştir. Matlab ortamında yapılan bu işlemler sonucunda MGN'de panele ait akım değeri elde edilmiştir.

\section{YSA YARDIMIYLA MGNT}

İnsan beyni milyarlarca birbiriyle bağlantılı nöronların oluşturduğu karmaşık bir ağ yapısından oluşur. Her bir nöron elektriksel sinyaller sayesinde birbiriyle haberleşerek gereken işlemleri yerine getirmektedir. YSA, insan beyninin bilgi işlem yapısından esinlenerek geliştirilmiş bir genel hesaplama yöntemidir.

Bu çalışmada maksimum güç noktasındaki akım değerini tespit etmek amacıyla YSA kullanılmıştır. YSA ile MGNT için ilk olarak problemle ilgili KC85t-Kyocera marka panele ait katalog verileri (Tablo 2) Matlab ortamında hazırlanmış olan arayüz yardımıyla elde edilmiştir. Çalışmada radyasyon, sıcaklık ve bu değerlerde panele ait maksimum güç noktasındaki akım değeri ağı eğitmek için seçilmiştir.

Tablo 2. Ağı eğitmek için kullanılan veri seti

\begin{tabular}{|c|c|c|c|c|c|}
\hline \multirow{2}{*}{$\begin{array}{l}\text { Veri } \\
\text { NO }\end{array}$} & \multicolumn{2}{|c|}{ GİRDí } & \multirow{2}{*}{$\begin{array}{l}\text { ÇIKTI(GERÇEK) } \\
\text { MGN'de akım (A) }\end{array}$} & \multirow{2}{*}{$\begin{array}{c}\text { AĞIN ÇIKTISI } \\
\text { MGN'de akım (A) }\end{array}$} & \multirow{2}{*}{$\begin{array}{c}\text { ÇIKTI-AĞIN ÇIKTISI } \\
\text { Ağın hatası (e) }\end{array}$} \\
\hline & $\operatorname{Radyasyon}\left(\mathbf{W} / \mathbf{m}^{2}\right)$ & Sıcaklık(C $\left.C^{\circ}\right)$ & & & \\
\hline 1 & 50 & 25 & 0,244719592 & 0,242011348 & 0,002708244 \\
\hline 25 & 250 & 45 & 0,038616251 & 0,086159906 & $-0,047543655$ \\
\hline 57 & 600 & 30 & 2,805988771 & 2,801526469 & 0,004462302 \\
\hline 100 & 1000 & 45 & 4,876340243 & 4,864291692 & 0,012048551 \\
\hline
\end{tabular}

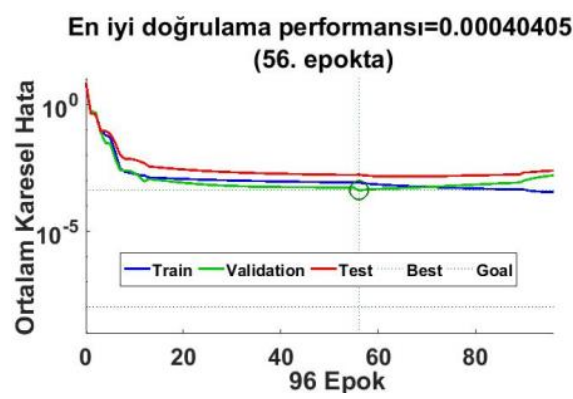

Şekil 7. YSA eğitim seyri

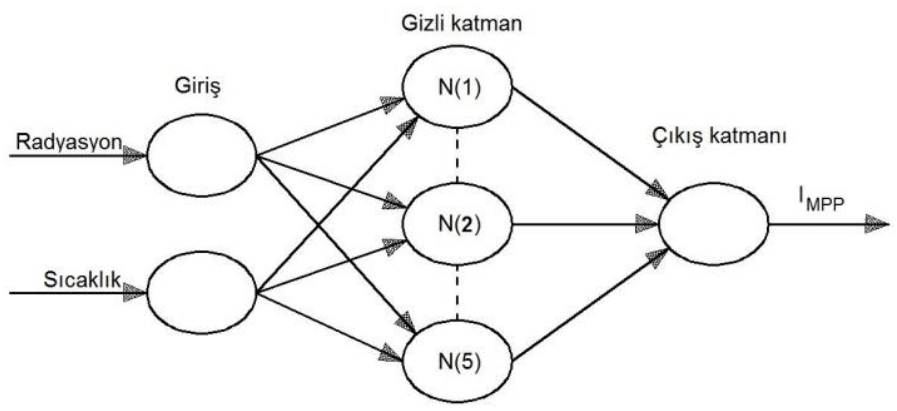

Şekil 8. MGNT için çalışılan ağ yapısı

Hangi eğitim algoritmasının kullanılacağı ve kaç katmanlı bir ağ oluşturulacağı tecrübe ile belirlenmektedir. Toplanan verilerin bir kısmı eğitim için bir kısmı ağın testi için ayrılmaktadır. Çalışmada toplanan verilerin $\% 70$ eğitim için \%30 test ve doğrulama için ayrılmıştır. Bu veriler, sıra dışında rastgele olarak ağ eğitiminde kullanılmıştır. Ortalama karesel hata belirlenen hatanın altında oluncaya kadar ağırlık ve biasların 
güncellenmesiyle ağ eğitilmektedir. Bu işlemler sonucunda, eğitilmiş ağ yardımıyla farklı ortam şartları için MGN' deki akım değerleri elde edilmektedir.

\section{CUK DÖNÜȘTÜRÜCÜ MATEMATIKSEL MODELİ}

$\mathrm{Bu}$ bölümde PV uygulamalarında çok sık kullanılan Cuk dönüştürücünün matematiksel modeli çıkartılmaktadır. Sonrasında modelle dayalı sürekli durum için PID denetleç tasarımı yapılmıştır. Cuk dönüştürücü, çıkış gerilimini giriş geriliminin polaritesine göre ters çevirerek çıkışa iletir. Devre şeması aşağıdaki şekilde gösterilmiştir.

$$
V_{C_{0}}=-\left(\frac{D}{1-D}\right) V_{g}
$$

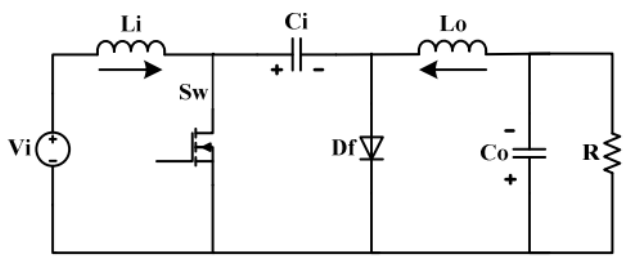

Şekil 9. Cuk dönüştürücülerin devre şeması

Cuk dönüştürücüler temel olarak ikişer adet bobin ve kondansatör, bir adet diyot ve bir anahtarlama elemanının bir araya gelmesiyle oluşmaktadır. Bobin, kondansatör ve direnç akımı, uygulanan gerilim ile orantılı bir şekilde değiştiği için lineer elemanlardır. Ancak devrede doğrusal olmayan devre elemanları diyot ve anahtar olması sebebiyle, dönüştürücünün denetlenebilmesi için lineerleştirme yapılmak zorundadır.

Sırasıyla Cuk dönüştürücünün iki farklı anahtarlama durumuna göre diferansiyel denklemleri yazılır. Sürekli hal ortalama değer yaklaşımı kullanılarak Cuk dönüştürücü matematiksel modeli elde edilir [14]. Son aşamada da elde edilen denetleç tasarımında kullanılacak olan Cuk dönüştürücünün küçük işaret modeli denklem 2'de verilmiştir.

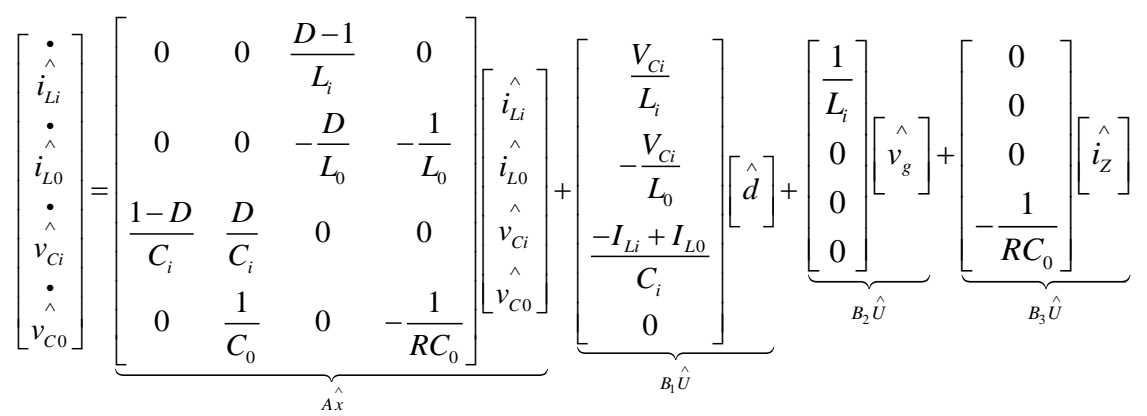

Cuk dönüştürücüye ait model $\hat{x}=A \hat{x}+B \hat{u}$ formunda elde edildi. Görev süresi panel çıkış gerilimi, bozucu yük akımı olmak üzere üç adet giriş işareti vardır. Denetleç tasarımında çalışma noktası için panel çıkış gerilimi ve yük akım değişimleri sıfır alınır.

Çıkış denklemi:

$$
\hat{y}=C \hat{x}+D \hat{u}
$$


Giriş işaretinin doğrudan çıkışa etkisi olmaması nedeniyle: $\mathrm{D}=0$

$$
[\begin{array}{c}
\left.\hat{i_{i}}\right] \\
\hat{y}
\end{array} \underbrace{\left[\begin{array}{llll}
1 & 0 & 0 & 0
\end{array}\right]\left[\begin{array}{c}
\hat{i_{L i}} \\
\hat{i_{L 0}} \\
\hat{v_{C i}} \\
\hat{v_{C 0}}
\end{array}\right]}_{C \hat{x}}+\begin{array}{c}
{[0]} \\
D \hat{u}
\end{array}
$$

PID denetleç tasarımı transfer fonksiyonuna dayalı yapılacağından Cuk dönüştürücünün transfer fonksiyonu durum denklemlerinin katsayılar matrisleri kullanılarak elde edilmiştir.

$$
\frac{\hat{i_{i}}}{\hat{d}}=C[s I-A]^{-1}[B]=\frac{9200 s^{3}+9.232 e 08 s^{2}+2.185 e 12 s+3.103 e 15}{s^{4}+1 e 05 s^{3}+2.023 e 08 s^{2}+2.269 e 11 s+1.171 e 14}
$$

PID tasarımı yöntemleri bu çalışmanın kapsamı dışında olduğundan Matlab ara yüz tasarımları kullanılarak PID katsayıları elde edilmiş ve aşağıda verilmiştir.

$$
\mathrm{Kp}=0.074, \mathrm{Ki}=39.9, \mathrm{Kd}=4.19 \mathrm{e}-06
$$
sunulmuştur.

Panelden maksimum gücün çekilebilmesi için önerilen yöntemlerin benzetim çalışması aşağıda

\section{BENZETIMM ÇALIŞMASI}

Bu bölümde KC85t-Kyocera marka fotovoltaik modül kullanılarak, YSA, BM ve D\&G tabanlı MGNT algoritmalarının değişken radyasyon $\left(400 \mathrm{~W} / \mathrm{m}^{2}-1000 \mathrm{~W} / \mathrm{m}^{2}-600 \mathrm{~W} / \mathrm{m}^{2}-800 \mathrm{~W} / \mathrm{m}^{2}-400 \mathrm{~W} / \mathrm{m}^{2}\right)$, farklı yükler $(20 \mathrm{ohm}$ - 50ohm) altında ve sabit sıcaklıkta $\left(25 \mathrm{C}^{\circ}\right)$ karşılaştırmalı benzetim çalışmaları yapılmıştır. PV panel çıkışından alınan güç ölçümleri de aşağıda sunulmuştur. Şekil 10' da çalışmadaki radyasyon değişimi ve Tablo 3, Tablo 4'de kullanılan PV panel karakteristiği gösterilmektedir.

Tablo 3. Kullanılan PV panel karakteristiği

\begin{tabular}{|l|c|}
\hline $\begin{array}{l}\text { Standart şartlarda fotovoltaik modülün } \\
\text { elektriksel performansı (KC85T) }\end{array}$ & Değer \\
\hline Maksimum Güç(Pmax) & $87.35 \mathrm{~W}$ \\
\hline MGN'deki gerilim(Vmgn) & $17.4 \mathrm{~V}$ \\
\hline MGN'deki akım(Imgn) & $5.02 \mathrm{~A}$ \\
\hline Açık devre gerilim(Voc) & $21.7 \mathrm{~V}$ \\
\hline K1sa devre akımı(Isc) & $5.35 \mathrm{~A}$ \\
\hline Modül başına hücre sayısı & 36 \\
\hline
\end{tabular}

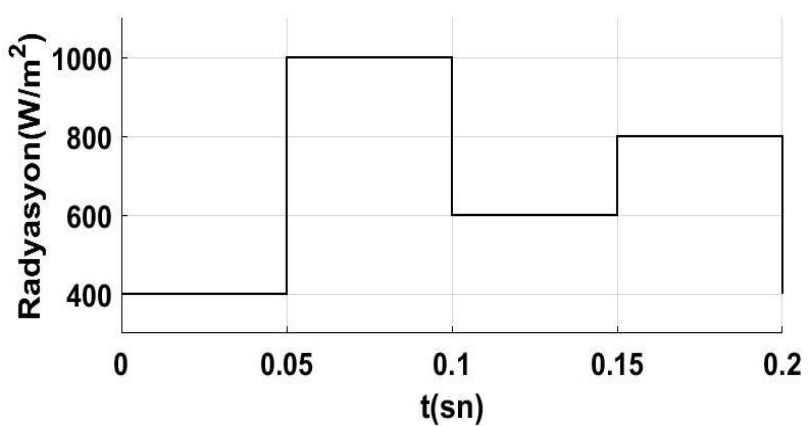

Şekil 10. Basamak radyasyon değişimi 
Tablo 4. Kullanılan PV panelin farklı radyasyonlar için MGN'deki güç değerleri $\left(25 \mathrm{C}^{\circ}\right)$

\begin{tabular}{|c|l|c|c|c|c|}
\hline \multirow{2}{*}{$\mathbf{T}=\mathbf{2 5} \mathbf{C}^{\circ}$} & Radyasyon $\left(\mathbf{W} / \mathbf{m}^{2}\right)$ & $\mathbf{4 0 0}$ & $\mathbf{1 0 0 0}$ & $\mathbf{6 0 0}$ & $\mathbf{8 0 0}$ \\
\cline { 2 - 6 } & MPP'de Güç (W) & 32.59 & 87.35 & 50.36 & 68.4 \\
\hline
\end{tabular}

Bu çalışmada kullanılan D\&G, BM ve YSA tabanlı MGNT uygulamalarının benzetim şeması aşağıda sunulmuştur.

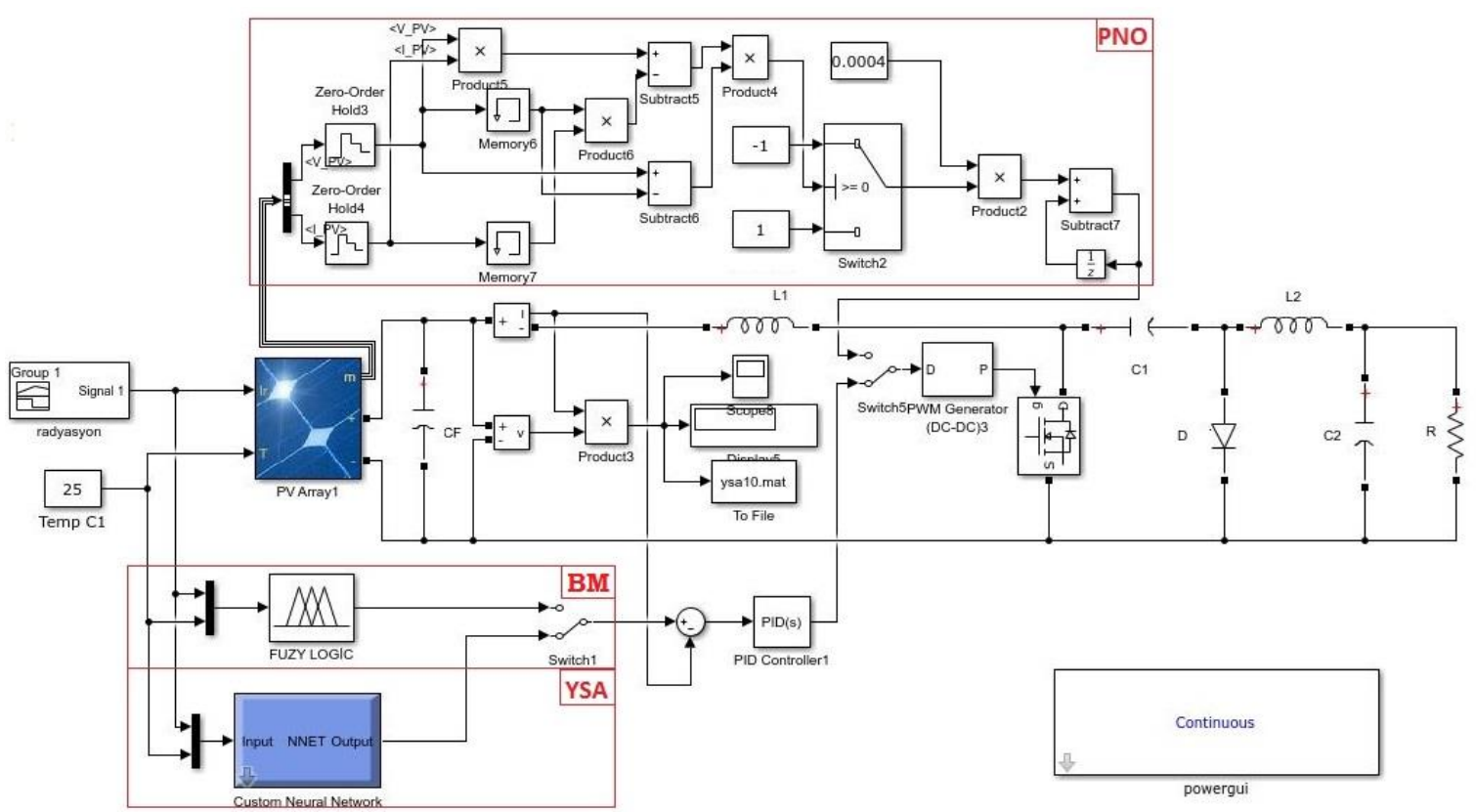

Şekil 11. MGNT benzetim şeması

Şekil 12'de sabit sicaklık $\left(25 \mathrm{C}^{\circ}\right)$, değişken radyasyonda $\left(400 \mathrm{~W} / \mathrm{m}^{2}-1000 \mathrm{~W} / \mathrm{m}^{2}-600 \mathrm{~W} / \mathrm{m}^{2}-800 \mathrm{~W} / \mathrm{m}^{2}-\right.$ $\left.400 \mathrm{~W} / \mathrm{m}^{2}\right)$ ve sabit yük $(20 \mathrm{ohm})$ altında, Cuk dönüştürücü kullanılarak BM ve $4 \mathrm{e}-4$ adım aralığına sahip olan D\&G tabanlı takip algoritmalarıyla panel çıkışındaki güç eğrisi görülmektedir. Şekil 13' de ise sabit sıcaklık $\left(25 \mathrm{C}^{\circ}\right)$, değişken radyasyonda $\left(400 \mathrm{~W} / \mathrm{m}^{2}-1000 \mathrm{~W} / \mathrm{m}^{2}-600 \mathrm{~W} / \mathrm{m}^{2}-800 \mathrm{~W} / \mathrm{m}^{2}-400 \mathrm{~W} / \mathrm{m}^{2}\right)$ ve sabit yük $(20 \mathrm{ohm})$ altında, Cuk dönüştürücü kullanılarak BM ve YSA tabanlı takip algoritmalarıyla panel çıkışındaki güç eğrisi görülmektedir.

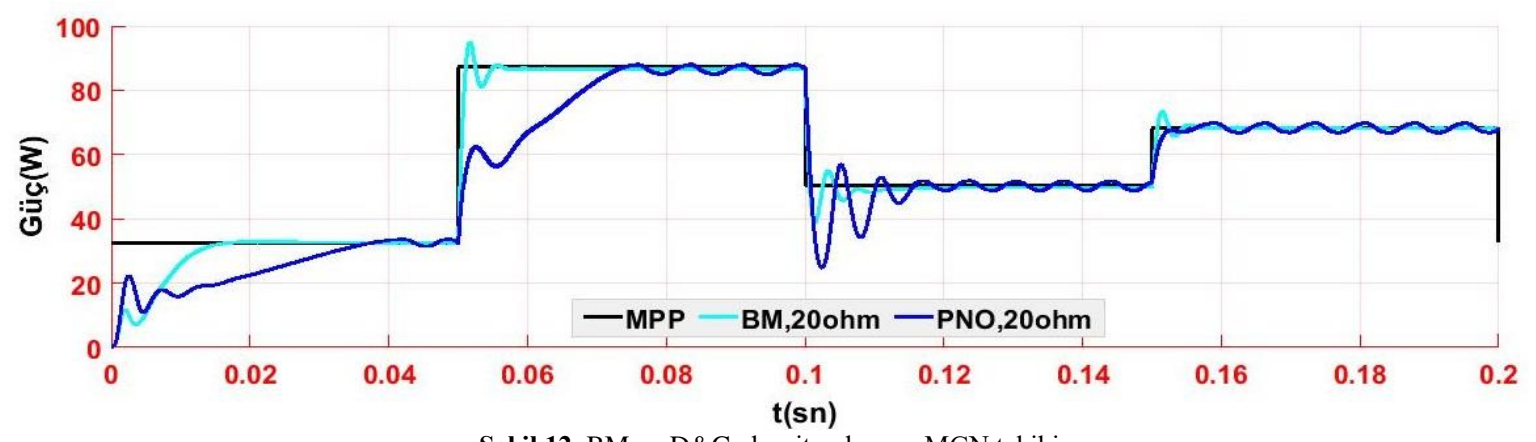

Şekil 12. BM ve D\&G algoritmalarının MGN takibi 
Tablo 5. BM ve D\&G algoritmalarının MGN performansları

\begin{tabular}{|c|c|c|c|c|c|c|c|}
\hline Radyasyon & Yük=20 $\Omega$ & D\&G(4e-4) & BM & Radyasyon & Yük=20 $\Omega$ & D\&G(4e-4) & $\mathbf{B M}$ \\
\hline \multirow{3}{*}{$400 \mathrm{~W} / \mathrm{m}^{2}$} & $\operatorname{MPP}(\mathbf{W})$ & 32.55 & 32.57 & \multirow{3}{*}{$600 \mathrm{~W} / \mathrm{m}^{2}$} & $\operatorname{MPP}(\mathbf{W})$ & 50.35 & 49.81 \\
\hline & Y.Zamanı (sn) & 0.042 & 0.017 & & Y.Zamanı (sn) & 0.1117 & 0.1265 \\
\hline & Salınım (W) & 2.15 & 0.69 & & Salınım (W) & 2.9 & 0.69 \\
\hline \multirow{3}{*}{$1000 \mathrm{~W} / \mathrm{m}^{2}$} & $\operatorname{MPP}(W)$ & 86.26 & 86.62 & \multirow{3}{*}{$800 \mathrm{~W} / \mathrm{m}^{2}$} & $\operatorname{MPP}(\mathbf{W})$ & 68.255 & 68.18 \\
\hline & Y.Zamanı (sn) & 0.075 & 0.06 & & Y.Zamanı (sn) & 0.1583 & 0.1575 \\
\hline & Salınım (W) & 2.89 & 0.88 & & Salınım (W) & 2.83 & 0.74 \\
\hline
\end{tabular}

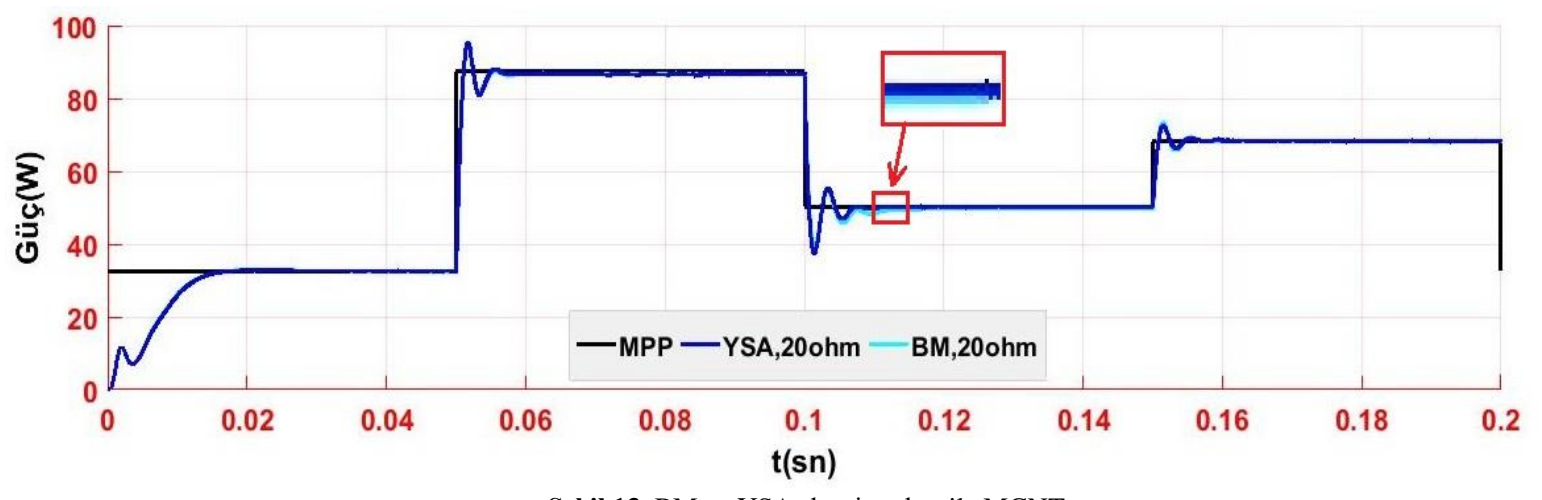

Şekil 13. BM ve YSA algoritmaları ile MGNT

Tablo 6. BM ve YSA algoritmaları ile MGNT performansları

\begin{tabular}{|c|c|c|c|c|c|c|c|}
\hline Radyasyon & Yük=20 $\Omega$ & YSA & $\mathbf{B M}$ & Radyasyon & Yük $=20 \Omega$ & YSA & $\mathbf{B M}$ \\
\hline \multirow{3}{*}{$400 \mathrm{~W} / \mathrm{m}^{2}$} & MPP (W) & 32.57 & 32.57 & \multirow{3}{*}{$600 \mathrm{~W} / \mathrm{m}^{2}$} & $\operatorname{MPP}(\mathbf{W})$ & 50.33 & 49.81 \\
\hline & Y.Zamanı (sn) & 0.017 & 0.017 & & Y.Zamanı (sn) & 0.107 & 0.1265 \\
\hline & Salınım (W) & 0.65 & 0.69 & & Salınım (W) & 0.75 & 0.69 \\
\hline \multirow{3}{*}{$1000 \mathrm{~W} / \mathrm{m}^{2}$} & $\operatorname{MPP}(\mathbf{W})$ & 86.66 & 86.62 & \multirow{3}{*}{$800 \mathrm{~W} / \mathrm{m}^{2}$} & $\operatorname{MPP}(\mathbf{W})$ & 68.42 & 68.18 \\
\hline & Y.Zamanı (sn) & 0.05 & 0.06 & & Y.Zamanı (sn) & 0.1555 & 0.1575 \\
\hline & Salınım (W) & 0.7 & 0.88 & & Salınım (W) & 0.77 & 0.74 \\
\hline
\end{tabular}

Şekil 14' de sabit sıcaklık $\left(25 \mathrm{C}^{\circ}\right)$, değişken radyasyonda $\left(400 \mathrm{~W} / \mathrm{m}^{2}-1000 \mathrm{~W} / \mathrm{m}^{2}-600 \mathrm{~W} / \mathrm{m}^{2}-800 \mathrm{~W} / \mathrm{m}^{2}-\right.$ $\left.400 \mathrm{~W} / \mathrm{m}^{2}\right)$ ve farklı yükler $(20 \mathrm{ohm}-50 \mathrm{ohm})$ altında, Cuk dönüştürücü kullanılarak $4 \mathrm{e}-4$ ve 2e-4 adım aralıklarına sahip olan D\&G tabanlı takip algoritmalarıyla panel çıkışındaki güç eğrisi görülmektedir. Şekil 15' de ise sabit sicaklık $\left(25 \mathrm{C}^{\circ}\right)$, değişken radyasyonda $\left(400 \mathrm{~W} / \mathrm{m}^{2}-1000 \mathrm{~W} / \mathrm{m}^{2}-600 \mathrm{~W} / \mathrm{m}^{2}-800 \mathrm{~W} / \mathrm{m}^{2}-400 \mathrm{~W} / \mathrm{m}^{2}\right)$ ve farklı yükler (20ohm-50ohm) altında, Cuk dönüştürücü kullanılarak BM ve YSA tabanlı takip algoritmalarıyla panel çıkışındaki güç eğrisi görülmektedir. 


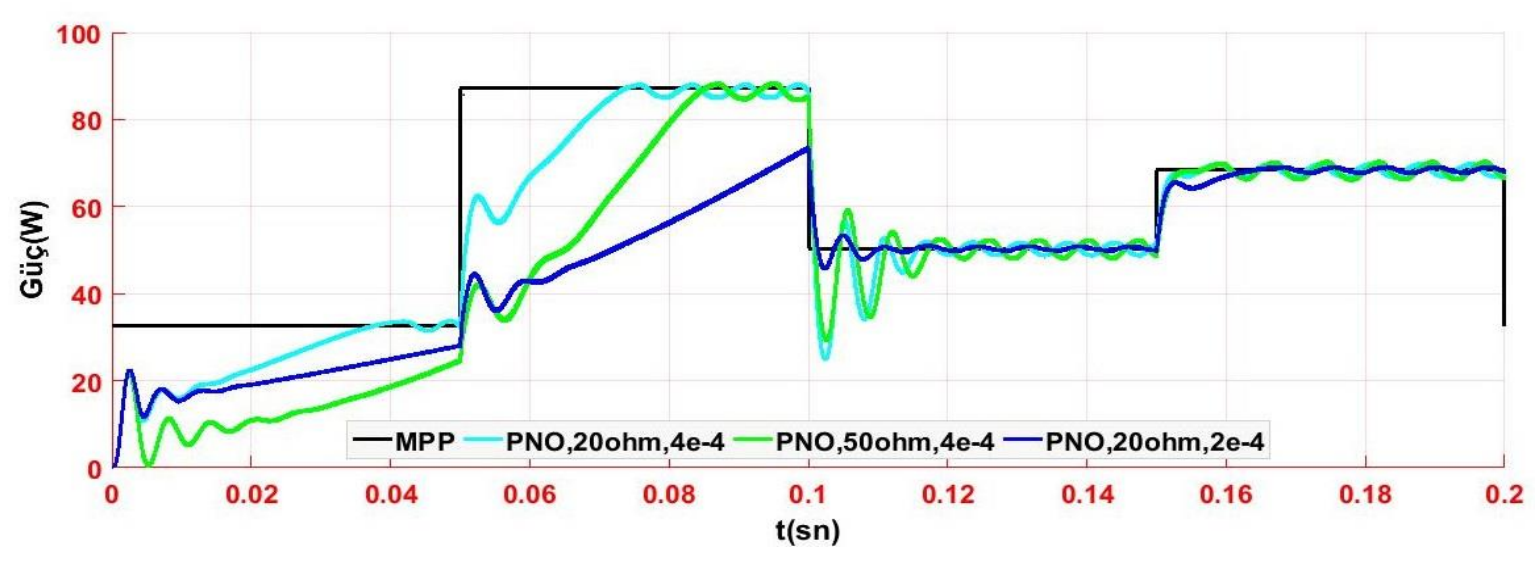

Şekil 14. $D \& G$ algoritmasının MGN takibi

Tablo 7. $D \& G$ algoritmasının MGNT performansları

\begin{tabular}{|c|c|c|c|c|c|c|c|}
\hline Radyasyon & Yük $=20 \Omega$ & D\&G(4e-4) & D\&G(2e-4) & Radyasyon & Yük $=20 \Omega$ & D\&G(4e-4) & D\&G(2e-4) \\
\hline \multirow{3}{*}{$400 \mathrm{~W} / \mathrm{m}^{2}$} & $\operatorname{MPP}(\mathbf{W})$ & 32.55 & - & \multirow{3}{*}{$600 \mathrm{~W} / \mathrm{m}^{2}$} & $\operatorname{MPP}(\mathbf{W})$ & 50.35 & 50.36 \\
\hline & Y.Zamanı(sn) & 0.042 & - & & Y.Zamanı(sn) & 0.1117 & 0.1108 \\
\hline & Salınım(W) & 2.15 & - & & Salınım(W) & 2.9 & 1.09 \\
\hline \multirow{3}{*}{$1000 \mathrm{~W} / \mathrm{m}^{2}$} & $\operatorname{MPP}(W)$ & 86.26 & - & \multirow{3}{*}{$800 \mathrm{~W} / \mathrm{m}^{2}$} & $\operatorname{MPP}(W)$ & 68.255 & 68.37 \\
\hline & Y.Zamanı(sn) & 0.075 & - & & Y.Zamani(sn) & 0.1583 & 0.1683 \\
\hline & Salınım(W) & 2.89 & - & & Salınım(W) & 2.83 & 1.43 \\
\hline & Yük $=50 \Omega$ & \multicolumn{2}{|c|}{ D\&G(4e-4) } & Radyasyon & $Y u ̈ k=50 \Omega$ & \multicolumn{2}{|c|}{ D\&G(4e-4) } \\
\hline \multirow{3}{*}{$400 \mathrm{~W} / \mathrm{m}^{2}$} & $\operatorname{MPP}(\mathbf{W})$ & \multicolumn{2}{|c|}{ - } & \multirow{3}{*}{$600 \mathrm{~W} / \mathrm{m}^{2}$} & $\operatorname{MPP}(\mathbf{W})$ & \multicolumn{2}{|c|}{50.33} \\
\hline & Y.Zamanı(sn) & \multicolumn{2}{|c|}{-} & & Y.Zamani(sn) & \multicolumn{2}{|c|}{0.1188} \\
\hline & Salınım(W) & \multicolumn{2}{|c|}{-} & & Salınım(W) & \multicolumn{2}{|c|}{4.04} \\
\hline \multirow{3}{*}{$1000 \mathrm{~W} / \mathrm{m}^{2}$} & $\operatorname{MPP}(\mathbf{W})$ & \multicolumn{2}{|c|}{86.4} & \multirow{3}{*}{$800 \mathrm{~W} / \mathrm{m}^{2}$} & $\operatorname{MPP}(\mathbf{W})$ & \multicolumn{2}{|c|}{68.18} \\
\hline & Y.Zamanı(sn) & \multicolumn{2}{|c|}{0.087} & & Y.Zamanı(sn) & \multicolumn{2}{|c|}{0.1592} \\
\hline & Salınım(W) & \multicolumn{2}{|c|}{3.62} & & Salınım(W) & \multicolumn{2}{|c|}{3.71} \\
\hline
\end{tabular}

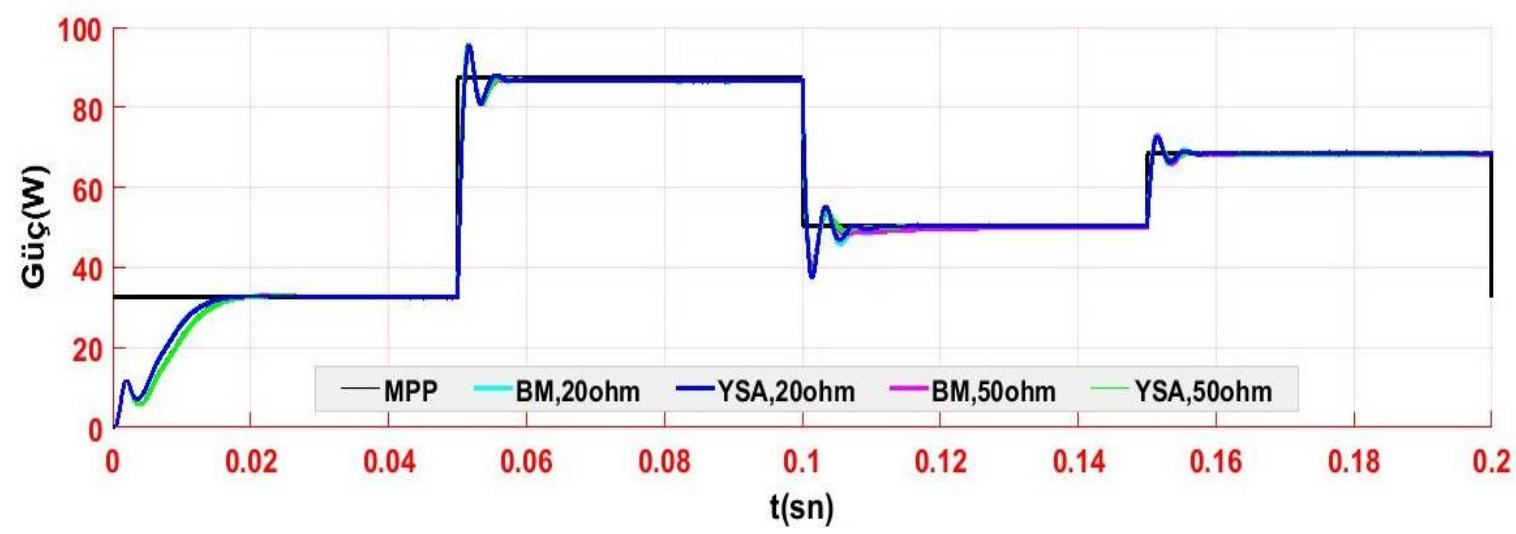

Şekil 15. BM ve YSA algoritmalarının MGN takibi 
Tablo 8. BM ve YSA algoritmalarının MGNT performansları

\begin{tabular}{|c|c|c|c|c|c|c|c|}
\hline Radyasyon & Yük $=50 \Omega$ & BM & YSA & Radyasyon & Yük=50 $\Omega$ & BM & YSA \\
\hline \multirow{3}{*}{$400 \mathrm{~W} / \mathrm{m}^{2}$} & $\operatorname{MPP}(\mathbf{W})$ & 32.56 & 32.58 & \multirow{3}{*}{$600 \mathrm{~W} / \mathrm{m}^{2}$} & $\operatorname{MPP}(\mathbf{W})$ & 49.84 & 50.42 \\
\hline & Y.Zamanı(sn) & 0.019 & 0.018 & & Y.Zamanı(sn) & 0.1271 & 0.108 \\
\hline & Salınım(W) & 0.75 & 0.78 & & Salınım(W) & 0.79 & 0.72 \\
\hline \multirow{3}{*}{$1000 \mathrm{~W} / \mathrm{m}^{2}$} & $\operatorname{MPP}(W)$ & 86.41 & 86.62 & \multirow{3}{*}{$800 \mathrm{~W} / \mathrm{m}^{2}$} & $\operatorname{MPP}(W)$ & 68.11 & 68.42 \\
\hline & Y.Zamanı(sn) & 0.055 & 0.055 & & Y.Zamanı(sn) & 0.1561 & 0.1557 \\
\hline & Salınım(W) & 0.61 & 0.81 & & Salınım(W) & 0.87 & 0.73 \\
\hline
\end{tabular}

Karşılaştırmalı olarak yapılan benzetim çalışmalarında yük değişiminin D\&G tabanlı güç takip algoritmasını etkilediği ve yüksek adım aralıklarında D\&G’nin MGN'ye çabuk ulaşırken, sürekli durumda salınım yaptığı görülmüştür (Tablo 7). D\&G algoritmasında küçük adım aralıkları kullanılır ise, MGN'ye ulaşmada gecikildiği ancak MGN'de az salınım yapıldı̆̆ı Şekil 14'de görülmektedir (Tablo 7). Bu nedenle D\&G algoritmasında gözlem değişkeninin adım aralığının belirlenmesi çok önemlidir.

Bulanık mantık tabanlı yapılan güç takibinin $D \& G$ ile yapılan güç takibinden daha başarılı olduğu Şekil 12 ve Tablo 5'de görülmektedir. Ancak BM tabanlı MGNT algoritmasının uygulanabilmesi için, Cuk dönüştürücünün matematiksel modelinin çıkartılarak bir denetleç tasarlanması gerektiği için BM tabanlı MGNT algoritması D\&G tabanlı MGNT algoritmasından daha karmaşıktır.

YSA tabanlı yapılan güç takibi ise diğer iki uygulanan algoritmadan daha başarılıdır (Tablo 6,8). Ancak YSA tabanlı güç takibi yapılabilmesi için dönüştürücünün modellenmesine ilave olarak panele ait eski verilere de ihtiyaç duyulmaktadır. Çalışmamızda panele ait veriler Matlab ortamında elde edilmiştir. Ancak gerçek uygulamalarda panel kirlenmesi, kısmi gölgelenme ve panellerin yıllar içerisindeki verimlerinin azalması gibi bozucu etmenlerde var olacaktır. Gerçek uygulamalarda MGNT’nin performansını artırmak için, YSA'ya veri seti oluştururken bu durumlarda göz önüne alınmalıdır.

\section{SONUÇLAR}

Yapılan benzetim çalışmalarında panel iç direncinin altında ve üstünde olabilecek bütün dirençlerde MGN takibi yapabilen Cuk dönüştürücü kullanarak, sadece MGNT algoritmalarının MGNT'ye etkisi sunulmuştur. Yukarıda yapılan çalışmalar 1şı̆̆ında D\&G algoritmasının adım aralığının belirlenmesinin çok önemli olduğu ve de yük değişiminin D\&G tabanlı yapılan MGNT performansını etkilediği görülmüştür (Şekil 14,Tablo 7). YSA ve BM tabanlı yapılan MGNT'nin yük değişiminden etkilenmediği ortaya koyulmuştur (Şekil 15,Tablo 8). Ancak BM uygulamalarında ilgili parametrelerin belirlenmesinde uzman bilgisine aşırı gereksinim duyulmasından dolayı sistem veriminin düşük olabileceği gösterilmiştir (Şekil 13,Tablo 6). YSA tabanlı yapılan güç takibinde ise eski verilerin toplanması nedeni ile maliyetli ve denetleç tasarımı gerektirmesinden dolayı karmaşık bir yapıda olsa da, en iyi performansı sergilediği görülmüştür. Ancak sezgisel yöntemleri kullanarak yapmış olduğumuz MGNT uygulamalarını gerçek uygulamalara aktarılırken ortam şartları gözetilerek (panel kirlenmesi ve verim kaybı vb.) veri seti ve üyelik fonksiyonları yeniden oluşturulması gerekecektir. Klasik D\&G tabanlı MGNT algoritması gibi akım ve gerilim girişli MGNT algoritmaları çevre şartlarından daha az etkilenerek MGNT yapabilmektedir.

$\mathrm{Bu}$ çalışma, dönüştürücü katmanının etkisi göz ardı edilerek (PV panel çıkışından güç ölçümü yapılarak) doğrudan (D\&G) ve dolaylı (BM, YSA) MGNT algoritmalarının performans analizlerini yaparak, gelecek çalışmalarda araştırmacıların MGNT algoritmalarını seçmelerine yardımcı olacaktır.

\section{KAYNAKLAR}

[1] Shirguppi, R. N., Kulkarni, S. G., Joshi, A. N. (2018). A survey on the evolution of solar cell materials. International Journal Of Advance Research, Ideas And Innovations In Technology, 4(4), 116-121.

[2] Radjai, T., Rahmani, L., GAUBERT, J., \& Gassab, S. (2014). Fuzzy Logic Variable Step of P\&O MPPT with Direct Control Method Using Cuk Converter. In Proc. 11th International Conference On Modeling and Simulation of Electric Machines, Converters and Systems, Valencia, Spain, ELECTRIMACS-2014 (pp. 324-329). 
[3] Macaulay, J., \& Zhou, Z. (2018). A Fuzzy Logical-Based Variable Step Size P\&O MPPT Algorithm for Photovoltaic System. Energies, 11(6), 1340.

[4] Chung, T. M., Daniyal, H., Sulaiman, M. H., \& Bakar, M. S. (2016). Comparative study of P\&O and modified incremental conductance algorithm in solar maximum power point tracking. 4th IET Clean Energy and Technology Conference (CEAT 2016), 36-43.

[5] Özdemir, A., \& Güngör, O. Güneş Panellerinde Hibrit ve YSA Tabanlı Algoritmalar ile Güç Takibi. Kahramanmaraş Sütçü İmam Üniversitesi Mühendislik Bilimleri Dergisi, 21(3), 258-266.

[6] Güngör, O., Özdemir, A., \& Elektrik-Elektronik, S. Ü. M. F. (2018). Güneș Panellerinde IC Ve ANFIS Tabanlı MPPT Algoritmalarının Karşılaştırmalı Performans Analizi. Journal of Institue Of ScienceandTechnology, 34 (2), 50-59.

[7] Güngör, O., \& Hussaini, M. Uyarlamalı Ağ Tabanlı Bulanık Çıkarım Sistemi ve Bulanık Mantık Tabanlı MPPT Tasarımı ve Kiyaslanması. EMO BİLIMSEL DERGİ, 7(14), 13-20.

[8] Kotak, V. C., \& Tyagi, P. (2013). DC to DC Converter in maximum power point tracker. International Journal of Advanced Research in Electrical, Electronics and Instrumentation Engineering, 2(12), 61156125 .

[9] Safari, A., \& Mekhilef, S. (2011). Simulation and hardware implementation of incremental conductance MPPT with direct control method using cuk converter. IEEE transactions on industrial electronics, 58(4), 1154-1161.

[10] Liu, X. (2004). An improved perturbation and observation maximum power point tracking algorithm for PV panels (Doctoral dissertation, Concordia University).

[11] Rahman, M. W., Bathina, C., Karthikeyan, V., \& Prasanth, R. (2016, January). Comparative analysis of developed incremental conductance (IC) and Perturb \& Observe (P\&O) MPPT Algorithm for Photovoltaic Applications. In 2016 10th International Conference on Intelligent Systems and Control (ISCO) IEEE. (pp. 1-6).

[12] Radjai, T., Rahmani, L., GAUBERT, J., \& Gassab, S. (2014). Fuzzy Logic Variable Step of P\&O MPPT with Direct Control Method Using Cuk Converter. In Proc. 11th International Conference On Modeling and Simulation of Electric Machines, Converters and Systems, Valencia, Spain, ELECTRIMACS-2014 (pp. 324-329).

[13] Kasbi, S., Rijanto, E., Nugroho, A., \& Ghani, R. A. (2017). Comparison of Fuzzy Logic and PI MPPT Algorithm with Indirect Controller for PV Systems. International Journal of Innovative Studies in Sciences and Engineering Technology, 3(8), 25-31.

[14] Middlebrook, R. D., \& Ćuk, S. (1977). A general unified approach to modelling switching-converter power stages. International Journal of Electronics Theoretical and Experimental, 42(6), 521-550. 